\title{
Observer Differences in Color-Mixture Functions Studied by Means of a Pair of Metameric Grays
}

\author{
Kenneth L. Kelly
}

\begin{abstract}
The Granville metameric gray panels have served to characterize the color vision of observers in an approximate but useful way. Thus, the 39 observers studied, and the four color-mixture functions were classed into five groups according to their indicated amounts of ocular pigmentation. These panels were also used to measure the correlation of lens and macular pigmentations with observer age, sex, and eye and hair colors. Of the three sets of color-mixture functions intended to refer to $2^{\circ}$ field observation, the 1931 Commission Internationale de L'Eclairage standard observer agrees best. These data thus afford no basis for supplanting the 1931 Commission Internationale de L'Éclairage standard observer with either the Judd "i" or the 1955 Stiles' $2^{\circ}$ color-mixture tunctions. The 1955 Stiles' $10^{\circ}$ functions, however, agree fairly well.
\end{abstract}

\section{Introduction}

The standard observer and coordinate system, now widely used in the interpretation of spectrophotometric and colorimetric data, were recommended in 1931 by the CIE (the Commission Internationale de L'Éclairage) for this purpose so that all subsequent data would be expressed in the same tristimulus system and would therefore be immediately comparable. This system was based on the work done by Guild and by Wright in England and until recently has proved quite satisfactory. However, it was reported to fail in several instances to account correctly for the differences in color between two samples whose spectrophotometric curves differ in the short wavelength end of the spectrum, especially below $420 \mathrm{~m} \mu$.

These reported failures resulted in much discussion looking toward a possible revision of this standard observer and led Judd to suggest in 1951 a modified set of color-mixture functions based on the data of Wright and Guild combined with the standard luminosity function modified below $460 \mathrm{~m} \mu$ according to luminous-efficiency data by Gibson-Tyndall, Wald, Weaver, Thomson, and Ishak. Now Dr. W. S. Stiles of the National Physical Laboratory in England has undertaken the first careful direct determination of the color-mixture functions of average normal observers which the standard observer should represent.

In these discussions, use of a field size larger than the $2^{\circ}$ field used for the 1931 standard observer has been advanced to accord more closely with viewing conditions in industry. Dr. Stiles is therefore making his measurements with both $2^{\circ}$ and $10^{\circ}$ fields and has already reported color-mixture data for a pilot group of 10 observers whose average age is about 31 yr $[8] .^{1}$

In 1949, Walter Granville, then of the Container Corp. of America, painted several metameric gray panels to illustrate the possible effect of angular subtense on color matching [2]. Two of these were chosen for the work herein reported; a nearly nonselective gray produced by a mixture of white and

\footnotetext{
1 Figures in brackets indicate the literature references at the end of this paper.
}

black pigments called the simplex gray (No. 1), and a selective gray produced by a mixture of yellow, green, purple, and white pigments called the complex gray (No. 8). Figure 1 and table 1 show the spectral directional reflectances of these two grays obtained on the General Electric recording spectrophotometer.

According to the 1931 standard observer, the complex gray will appear greener in daylight (source C) than the simplex, and the reverse will be true when source A (color temperature $2,854^{\circ} \mathrm{K}$, representative of incandescent lamp light) is used. The same effect results from changing the angular subtense of the sample from $10^{\circ}$ to $2^{\circ}$; the retinal area stimulated first will include the macula and also a portion of the surrounding retina, and second will lie inside the macula only. This change from $10^{\circ}$ to $2^{\circ}$ will have an effect at least partly analogous to placing a yellow filter (macular pigment) in front of the eye for the $10^{\circ}$ condition and, thus should have somewhat the same effect as reducing the color temperature of the source.

The purpose of the present study is to establish a criterion by means of which it will be possible to determine whether any set of color-mixture functions gives predictions of the character of the color difference between the Granville grays in accord with observers known to have normal vision by the ac-

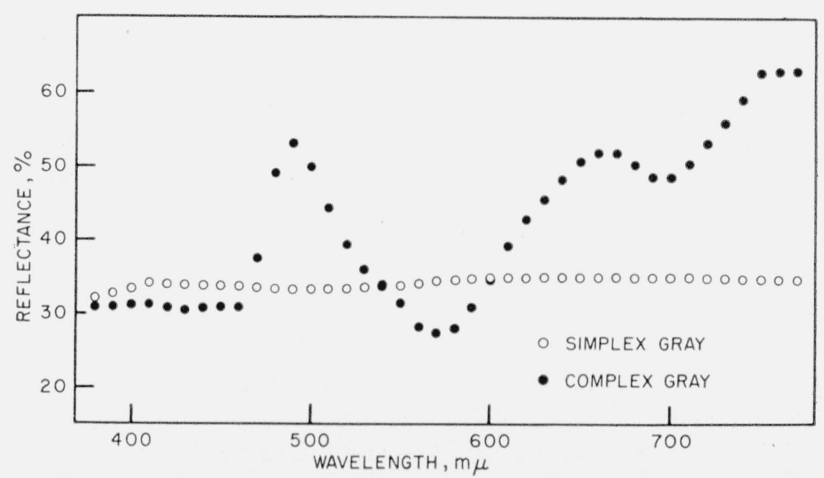

Figure 1. Spectrophotometric curves of the two metameric Granville grays. 
TABle 1. Spectral directional reflectances of the two Granville grays

\begin{tabular}{|c|c|c|}
\hline Wavelength & Simplex (No. 1) & Complex (No. 8) \\
\hline $\begin{array}{l}380 \\
390\end{array}$ & $\begin{array}{r}\text { a } 0.317 \\
\text { a. } 324\end{array}$ & $\begin{array}{r}\text { a } 0.305 \\
\text { a. } 307\end{array}$ \\
\hline 400 & .331 & .309 \\
\hline 410 & .338 & .310 \\
\hline 420 & .337 & .304 \\
\hline 430 & .336 & .301 \\
\hline 440 & .335 & .305 \\
\hline 450 & .334 & .306 \\
\hline 460 & $\begin{array}{l}.307 \\
.334\end{array}$ & .316 \\
\hline 470 & .332 & .373 \\
\hline 480 & .331 & .488 \\
\hline 490 & .330 & .528 \\
\hline 500 & .330 & .497 \\
\hline 510 & .331 & .441 \\
\hline 520 & .331 & .391 \\
\hline $\begin{array}{l}530 \\
540\end{array}$ & $\begin{array}{l}.332 \\
.334\end{array}$ & .357 \\
\hline & & \\
\hline 560 & .356 & $\begin{array}{r}.311 \\
.289\end{array}$ \\
\hline 570 & .342 & .281 \\
\hline 580 & .343 & .287 \\
\hline 590 & .345 & .306 \\
\hline 600 & .346 & .342 \\
\hline 610 & .347 & .389 \\
\hline 620 & .347 & .425 \\
\hline 630 & .347 & .452 \\
\hline 640 & .347 & .480 \\
\hline 650 & .347 & \\
\hline 660 & .348 & .517 \\
\hline 670 & .347 & .516 \\
\hline 680 & $\begin{array}{l}347 \\
348\end{array}$ & .500 \\
\hline & & \\
\hline 700 & $\begin{array}{l}.348 \\
348\end{array}$ & $\begin{array}{r}.483 \\
502\end{array}$ \\
\hline 710 & .348 & $\begin{array}{l}.502 \\
528\end{array}$ \\
\hline $\begin{array}{l}720 \\
730\end{array}$ & $\begin{array}{r}347 \\
.346\end{array}$ & .528 \\
\hline 740 & 346 & $\begin{array}{r}.500 \\
.589\end{array}$ \\
\hline 750 & .345 & .626 \\
\hline 760 & a. 344 & a. 627 \\
\hline 770 & a. 343 & a. 627 \\
\hline
\end{tabular}

a Extrapolated.

cepted tests. In particular, this criterion is to be applied to the four sets of color-mixture functions already mentioned.

\section{Experimental Method}

The experiment consisted of placing the two gray panels side by side in a nearly vertical position illuminated by CIE source $A$ and viewing them through a Davis-Gibson (CIE) C filter prepared in February 1955. The spectral transmittances of this filter determined in July 1956 at the start of the observations are given in table 2. The observer was asked to stand at a line that would cause the retinal image of the two panels to subtend a $10^{\circ}$ angle and to disregard the Maxwell spot [7] if present. First he was to describe the color of the simplex gray with respect to that of the complex gray and then, as the operator reduced the voltage on the lamp and thereby its color temperature, to note when neither panel appeared redder or greener than the other. The voltage of the source at this point was recorded along with the observer's age, sex, and hair and eve colors. Observers not passing the 5th Edition Ishihara Tests for Colour Blindness were eliminated.
TABLE 2. The spectral transmittances and change in reciprocal color temperature for the daylight filters used

\begin{tabular}{|c|c|c|c|c|c|}
\hline $\begin{array}{l}\text { Wave- } \\
\text { length }\end{array}$ & $\begin{array}{l}\text { Davis-Gibson } \\
\text { "C" }\end{array}$ & $\begin{array}{c}\text { Filter G90A } \\
2.13 \mathrm{~mm}\end{array}$ & $\begin{array}{l}\text { Davis-Gib- } \\
\text { son plus } \\
\text { G90A }\end{array}$ & $\begin{array}{l}\text { Filter No. } \\
\quad 8331\end{array}$ & $\begin{array}{l}\text { Davis-Gib- } \\
\text { Son plus } \\
\text { No. } 8331\end{array}$ \\
\hline $\begin{array}{l}m \mu \\
380 \\
390\end{array}$ & $\begin{array}{r}\text { a } 0.69 \\
\text { a. } 71\end{array}$ & $\begin{array}{l}\text { a } 0.751 \\
\text { a. } 774\end{array}$ & $\begin{array}{r}0.5182 \\
.5495\end{array}$ & $\begin{aligned} & \text { a } 0.47 \\
& \text { a. } 59\end{aligned}$ & $\begin{array}{r}0.32 \\
.42\end{array}$ \\
\hline 400 & .7268 & .7967 & .5790 & .685 & 498 \\
\hline 410 & .7501 & .8066 & .6050 & .712 & .534 \\
\hline 420 & .7475 & .7800 & .5830 & .656 & .490 \\
\hline 430 & .7180 & .7585 & .5446 & .617 & .443 \\
\hline 440 & . 6623 & .7279 & .4821 & .555 & .368 \\
\hline 450 & .5836 & .6982 & .4075 & . 498 & .291 \\
\hline 460 & .5090 & .6647 & .3383 & .440 & .224 \\
\hline 470 & .4557 & .6345 & .2891 & 388 & .177 \\
\hline 480 & .4056 & .6029 & .2445 & .344 & .140 \\
\hline 490 & .3532 & .5777 & .2040 & .309 & .109 \\
\hline 500 & .2956 & .5551 & . 1641 & .280 & .0828 \\
\hline 510 & .2479 & .5323 & $\begin{array}{l}1341 \\
.1320\end{array}$ & .254 & .0630 \\
\hline 520 & .2178 & .5088 & .1108 & .228 & .0497 \\
\hline 530 & .2027 & .4805 & .0974 & .199 & .0403 \\
\hline 540 & .1961 & .4602 & .0902 & .179 & .0351 \\
\hline 550 & 1891 & .4547 & .0860 & .172 & .0325 \\
\hline 560 & .1765 & .4600 & .0812 & .176 & .0311 \\
\hline 570 & .1600 & .4560 & .0730 & .171 & .0274 \\
\hline 580 & .1420 & .4310 & 0612 & .150 & .0213 \\
\hline 590 & .1250 & .3950 & .0494 & .119 & .0149 \\
\hline 600 & .1115 & .3805 & .0424 & .109 & .0122 \\
\hline 610 & .1015 & .3750 & .0381 & .103 & .0105 \\
\hline 620 & .0940 & .3650 & 0343 & .094 & .0088 \\
\hline 630 & . 0880 & .3498 & .0308 & .083 & .0073 \\
\hline 640 & .0825 & .3318 & .0274 & .072 & .0059 \\
\hline 650 & .0779 & .3207 & . 0250 & .066 & .0051 \\
\hline 660 & 0724 & 3217 & .0233 & .068 & .0049 \\
\hline 670 & .0684 & .3330 & .0228 & .072 & .0049 \\
\hline 680 & 0634 & .3493 & .0221 & .078 & .0049 \\
\hline 690 & .0584 & 3618 & .0211 & .083 & .0048 \\
\hline 700 & .0534 & . 3646 & .0195 & .082 & .0044 \\
\hline 710 & .0489 & .3626 & .0177 & .080 & .0039 \\
\hline 720 & .0444 & .3569 & .0158 & .076 & .0034 \\
\hline 730 & .0404 & $\begin{array}{l}3509 \\
.\end{array}$ & .0142 & .073 & .0029 \\
\hline 740 & . 0369 & .3463 & .0128 & .068 & .0025 \\
\hline 750 & .0344 & .3418 & 0118 & .067 & .0023 \\
\hline 760 & a. 033 & ฉ. 337 & .0111 & a. 066 & .0022 \\
\hline 770 & a. 032 & a. 333 & .0107 & a. 064 & .0020 \\
\hline$\Delta \mu \mathrm{rd}$ & 202.5 & 77.9 & 280.4 & 187.5 & 390.0 \\
\hline
\end{tabular}

a Extrapolated.

The observer was then asked to step back to another line from which the retinal image would subtend an angle of $2^{\circ}$ and the experiment was repeated. The combination of source and DavisGibson filter resulted in a maximum color temperature of $6,750^{\circ} \mathrm{K}$, but for those observers requiring a source of higher color temperature, one or more measured blue daylight glasses (table 2) were used with the Davis-Gibson filter. Therefore, by varying the voltage on the lamp and by using combinations of these filters, color temperatures could be obtained from $1,800^{\circ} \mathrm{K}$ up and, indeed, it was found that some sources bluer than a source corresponding to infinite color temperature were required. The voltage and filter combinations were noted for each red-green balance point for each observer and the corresponding reciprocal color temperatures were determined from table 3 by subtracting the change in microreciprocal degrees Kelvin ( $\mu \mathrm{rd}$ ) produced by the filter combination from the reciprocal color temperature of the bare lamp. 
TABLE 3. Color temperature $(\theta)$ in ${ }^{\circ} K$ of the lamp, and the reciprocal color temperature in $\mu$ rd of the lamp and the lamp with one or more of the daylight filters against voltage on the $\operatorname{lamp}$

\begin{tabular}{|c|c|c|c|c|c|c|}
\hline $\begin{array}{c}\text { Volt- } \\
\text { age }\end{array}$ & $\begin{array}{l}\Theta \text { of } \\
\text { lamp } \\
\text { alone }\end{array}$ & $\begin{array}{c}10^{6} / \Theta \\
\text { of } \\
\text { lamp }\end{array}$ & $\begin{array}{l}10^{6} / \Theta \text { of } \\
\text { lamp and } \\
\text { Davis- } \\
\text { Gibson } \\
\text { filter }\end{array}$ & $\begin{array}{c}10^{6} / \Theta \text { of } \\
\text { lamp and } \\
\text { Davis- } \\
\text { Gibson } \\
\text { with G90A }\end{array}$ & $\begin{array}{l}10^{6} / \Theta \text { of } \\
\text { lamp and } \\
\text { Davis- } \\
\text { Gibson } \\
\text { with } 8331\end{array}$ & $\begin{array}{c}10^{6} / \Theta \text { of } \\
\text { lamp and } \\
\text { Davis- } \\
\text { Gibson } \\
\text { with G90A } \\
\text { and } 8331\end{array}$ \\
\hline $\begin{array}{l}36.0 \\
42.7 \\
49.9 \\
57.6\end{array}$ & $\begin{array}{l}1800 \\
1900 \\
2000 \\
2100\end{array}$ & $\begin{array}{l}556 \\
526 \\
500 \\
476\end{array}$ & $\begin{array}{l}353 \\
324 \\
298 \\
274\end{array}$ & $\begin{array}{l}275 \\
246 \\
220 \\
196\end{array}$ & $\begin{array}{r}166 \\
137 \\
110 \\
86\end{array}$ & $\begin{array}{r}88 \\
58 \\
32 \\
8\end{array}$ \\
\hline $\begin{array}{l}66 \\
75 \\
84 \\
94\end{array}$ & $\begin{array}{l}2200 \\
2300 \\
2400 \\
2500\end{array}$ & $\begin{array}{l}455 \\
435 \\
417 \\
400\end{array}$ & $\begin{array}{l}252 \\
233 \\
214 \\
198\end{array}$ & $\begin{array}{l}174 \\
154 \\
137 \\
119\end{array}$ & $\begin{array}{l}65 \\
45 \\
27 \\
10\end{array}$ & $\begin{array}{l}-13 \\
-33 \\
-51 \\
-68\end{array}$ \\
\hline $\begin{array}{l}104 \\
115 \\
126 \\
133\end{array}$ & $\begin{array}{l}2600 \\
2700 \\
2800 \\
2854\end{array}$ & $\begin{array}{l}385 \\
370 \\
357 \\
350.4\end{array}$ & $\begin{array}{l}182 \\
168 \\
155 \\
149\end{array}$ & $\begin{array}{r}104 \\
90 \\
77 \\
70\end{array}$ & $\begin{array}{r}-5 \\
-20 \\
-33 \\
-40\end{array}$ & $\begin{array}{r}-83 \\
-98 \\
-111 \\
-118\end{array}$ \\
\hline
\end{tabular}

\section{Red-Green Balance Points for the Four Color-Mixture Functions}

The red-green balance points for the four colormixture functions were determined by first computing the chromaticity coordinates for the two gray panels for each of the functions for three Planckian sources $(277,221$, and $191 \mu \mathrm{rd})$, for nine Planckian sources $(666,571,500,488,486,444,400,350$, and $308 \mu \mathrm{rd})$ combined with the Davis-Gibson "C" filter $\left(\Delta 10^{6} / \Theta=202 \mu \mathrm{rd}\right)$, and for the same Planckian sources combined with the double filter DavisGibson "C" plus G90A $\left(\Delta 10^{6} / \theta=280 \mu \mathrm{rd}\right)$. These data were plotted on the $(\mathrm{x}, \mathrm{y})$-chromaticity diagram and fall close to the Planckian locus.

It was noted that the direction of the straigbt line connecting each pair of points as well as the distance between them (indicative of color difference) varies regularly with the correlated color temperature of the energy reflected by the simplex gray regardless of whether the computation is based on a Planckian source or on a Planckian source modified by the single or the double filter. Figure 2 shows the Planckian locus and 10 of the 21 pairs of computed points plotted on the (x,y)-diagram for the CIE standard observer. Note that near $300 \mu$ rd the simplex gray is seen by this observer as greener than the complex, whereas at source C $(148 \mu \mathrm{rd})$, the reverse is true.

The red-green balance points for the two Stiles color-mixture functions were easily determined because they each predicted that under a certain one of the illuminants the two gray panels would be a chromaticity match; that is, the chromaticity points for them were found not to be significantly different. The reciprocal color temperature of the source satisfying this condition for the Stiles' $2^{\circ}$ colormixture functions is $210 \mu \mathrm{rd}$, while that for the Stiles' $10^{\circ}$ color-mixture function is $267 \mu \mathrm{rd}$.

The other two color-mixture functions predict that at the red-green balance point there will be a residual yellow-blue difference. Therefore it was necessary to establish some criterion to determine when the red-green difference equals zero. The

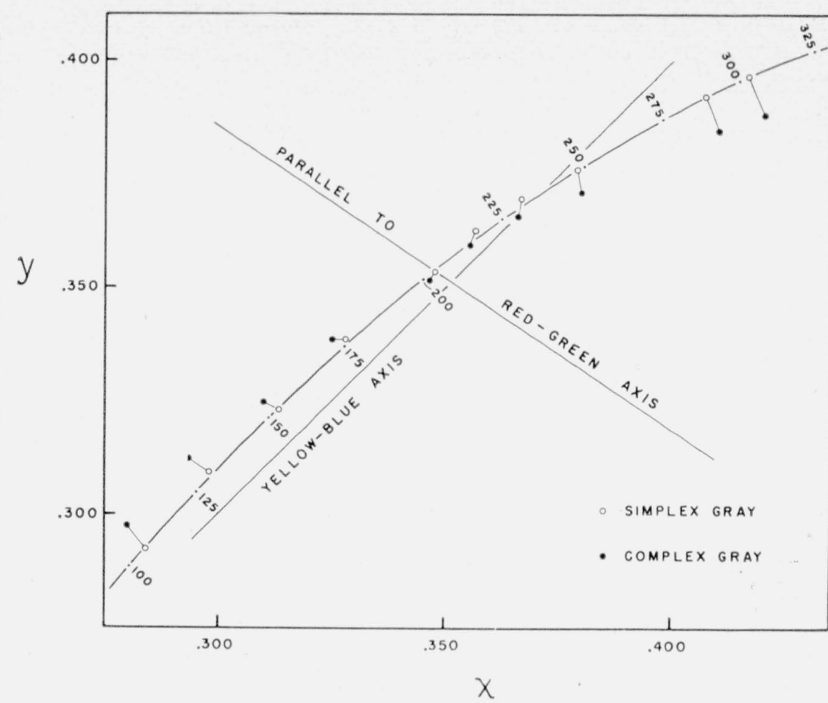

Figure 2. Illustration of the change in relative position and distance apart of the CIE $(x, y)$-points of the Granville grays as the color temperature of the source is changed.

first criterion used in determining the corresponding reciprocal color temperature of source was that the line joining the chromaticity points of the two grays be parallel to the yellow-blue axis on the (x,y)diagram. This axis, having an inclination of $45^{\circ}$, was drawn between the 476 and $578 \mathrm{~m} \mu$ points on the spectrum locus. These are the proposed centers of the yellow and blue segments of the boundary of real colors on this diagram [6]. The corresponding values of reciprocal color temperature of source satisfying this criterion for the 1931 CIE and 1951 Judd "i" color-mixture functions are 192 and 202 $\mu \mathrm{rd}$, respectively.

The second criterion used in determining the corresponding reciprocal color temperature of source was that the line joining the chromaticity points of the grays be perpendicular to the red-green axis on a uniform chromaticity scale diagram [4]. This axis was drawn from the $508 \mathrm{~m} \mu$ point on the spectrum locus to the intersection of the line drawn through the $493 \mathrm{~m} \mu$ point and the "C" illuminant point with the line connecting the red and violet ends of the spectrum locus. These are the proposed centers of the red and green segments of the boundary of real colors on the (x,y)-diagram [6].

A perpendicular to this axis was drawn through the "C" illuminant point and was found to intersect the spectrum locus at $567 \mathrm{~m} \mu$. This perpendicular was transferred to the (x,y)-diagram by drawing it also through the "C" illuminant point and the 567 $\mathrm{m} \mu$ point on the spectrum locus. The angle of inclination of this perpendicular is found to be $66.5^{\circ}$ and the corresponding values of the reciprocal color temperature of source satisfying this criterion for the two color-mixture functions are 206 and $213 \mu \mathrm{rd}$, respectively. Table 4 summarizes the values of reciprocal color temperature computed by these criteria to correspond to these balance points for the four sets of color-mixture functions. 
TABLE 4. Values of reciprocal color temperature of red-green balance points for the four color-mixture functions by different criteria

\begin{tabular}{|c|c|c|}
\hline Color-mixture functions & \multicolumn{2}{|c|}{$\begin{array}{l}\text { Reciprocal color temperature of } \\
\text { source in } \mu \text { rd yielding red-green } \\
\text { balance }\end{array}$} \\
\hline \multirow{3}{*}{$\begin{array}{l}\text { Stiles' } 2^{\circ} \\
\text { Stiles' } 10^{\circ}-\end{array}$} & \multicolumn{2}{|c|}{ By chromaticity match } \\
\hline & \multicolumn{2}{|c|}{$\begin{array}{l}210 \\
267\end{array}$} \\
\hline & $\begin{array}{l}\text { Parallel to } \mathrm{Y}-\mathrm{B} \\
\text { axis }\end{array}$ & $\begin{array}{l}\text { Perpendicular } \\
\text { on UCS triangle } \\
\text { to R-G axis }\end{array}$ \\
\hline $\begin{array}{l}1931 \text { CIE } \\
1951 \text { Judd "i" }\end{array}$ & $\begin{array}{l}192 \\
202\end{array}$ & $\begin{array}{l}206 \\
213\end{array}$ \\
\hline
\end{tabular}

\section{Results and Discussion}

Table 5 contains the individual data for the 39 observers studied with their descriptions of the two panels and the reciprocal color temperature of their red-green balance points. Note that observer 39 was able to obtain a match at the $10^{\circ}$ position but that it was not possible to run the lamp at a sufficiently high color temperature for him to obtain a match at the $2^{\circ}$ position, presumably due to his very heavy ocular pigmentation.

Because the image of a $2^{\circ}$ field falls wholly within the macula, the $2^{\circ}$-field results depend both on the macula and on the lens pigmentations. Likewise, since the image of a $10^{\circ}$ field covers the macula and a large region of the surrounding retina of which the area of the macula represents about 10 percent, the $10^{\circ}$-field results depend only on the lens pigmentation provided the observers disregard the Maxwell spot as instructed. Also, the difference between the two may be taken as a measure of the macular pigmentation on the assumption that the spectral sensitivities of the receptors apart from pigmentation are the same throughout the $10^{\circ}$ field [7].

The degree of pigmentation of an observer is indicated by his red-green balance point. By this interpretation, Stiles' $10^{\circ}$ average observer (balance point at $267 \mu \mathrm{rd}$, see table 4 ) would be the least pigmented of the four.

TABLE 5. Observer initials, age, sex, eye, and hair color, descriptions of colors of gray panels illuminated by source $C$ at the $10^{\circ}$ and $2^{\circ}$ positions, and reciprocal color temperature of source required by each observer for red-green balance at both positions and the difference between them

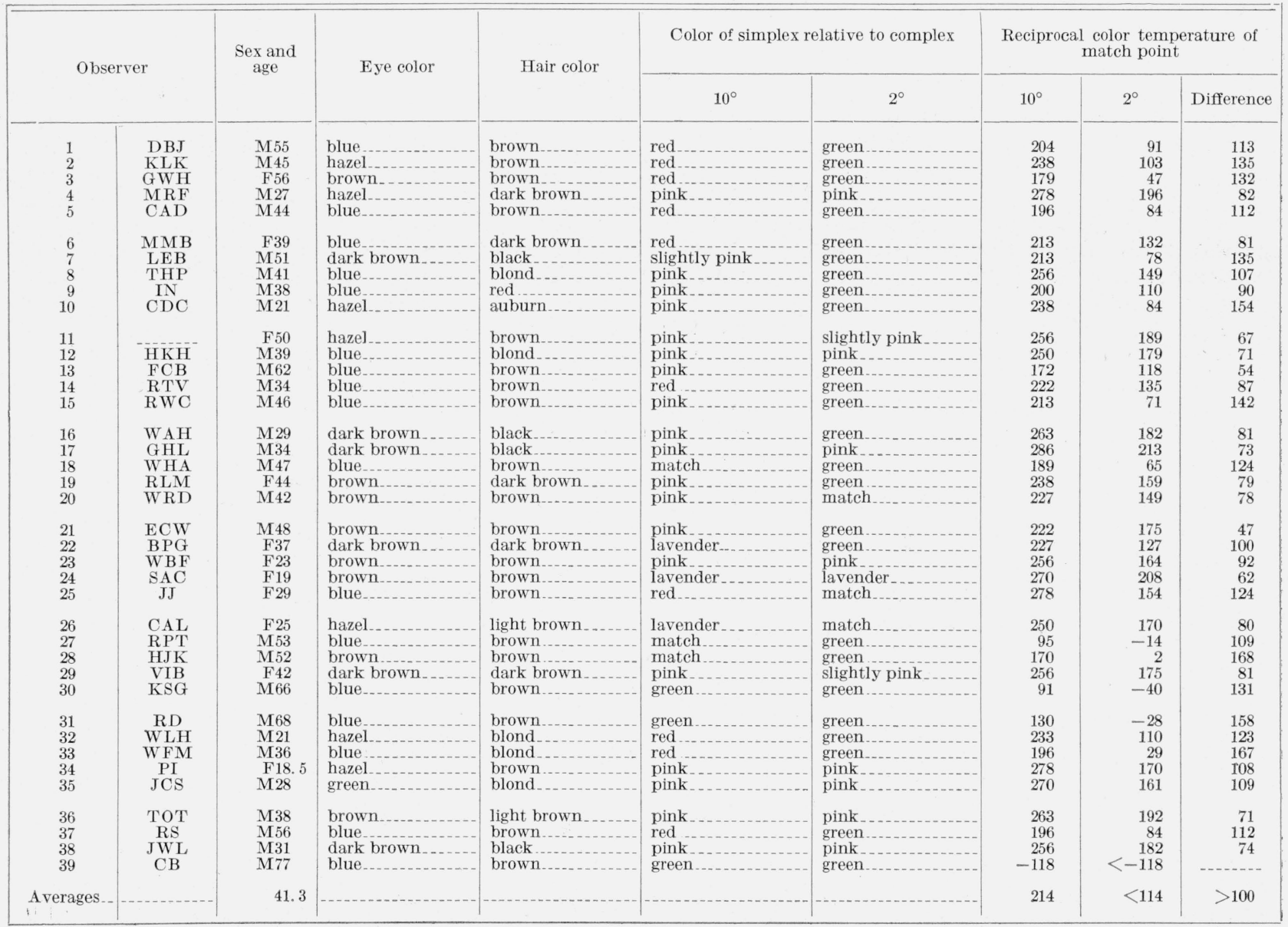




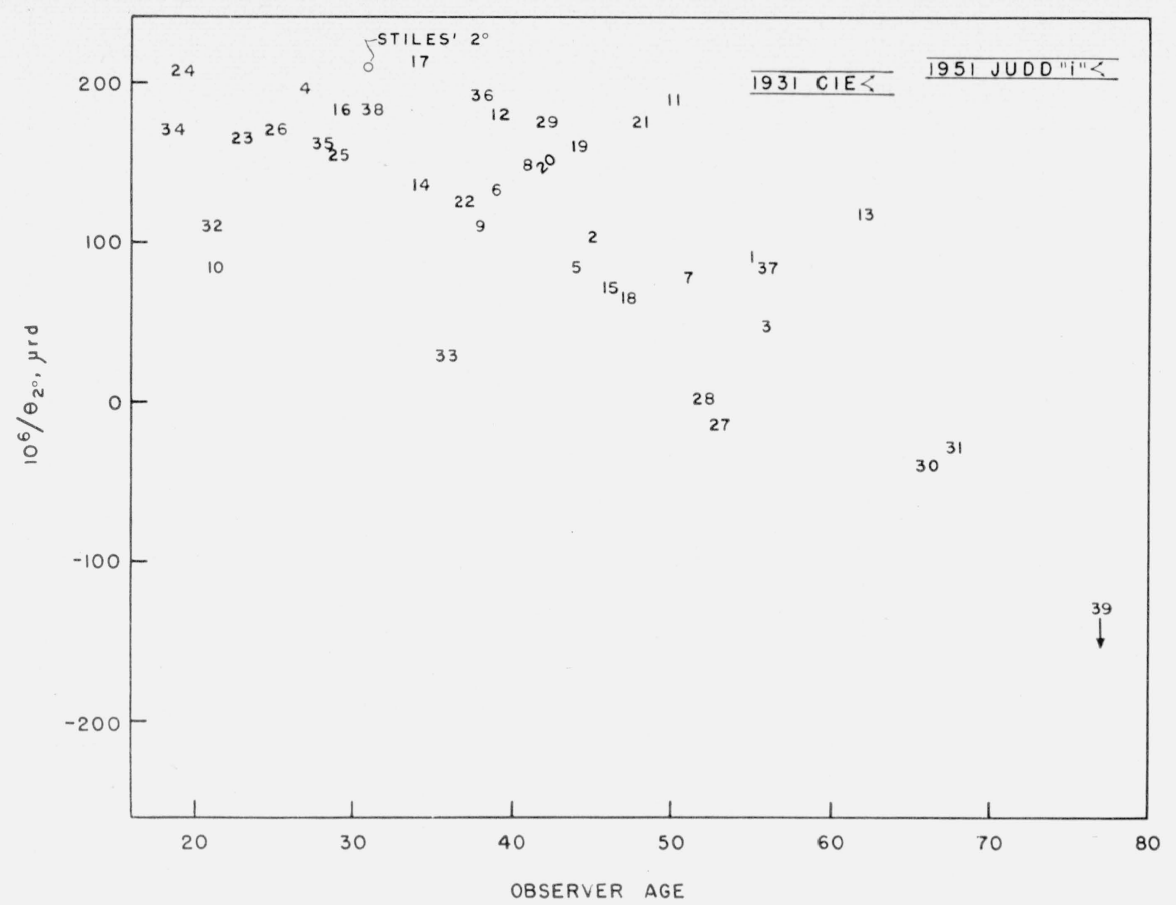

FIGURE 3. Reciprocal color temperature of source required in a $2^{\circ}$ field by 39 observers to produce red-green balance between the Granville grays plotted against observer age.

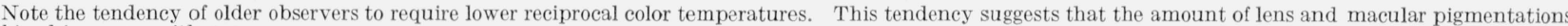
combined increases with age.

In figure 3 , the reciprocal color temperature $\left(10^{6} / \Theta_{2}\right)$ of the $2^{\circ}$ red-green balance points for the 39 observers studied (see table 5) are plotted with observer number against observer age. Since no age has been given for the 1931 CIE and 1951 Judd " $\mathrm{j}$ " color-mixture functions, the spread in reciprocal color temperatures required by them for red-green balance as given in table 4 , are indicated by a pair of lines which should extend across the graph but have been shown as short sections only to avoid complicating the figure. Stiles gives the average age of his pilot group of 10 observers as 31 . It may be seen from. figure 3 that only four of the 39 observers studied seem. to have less pigmentation than the 1931 CIE standard observer, only two less than the 1951 Judd "i" (both of these on the basis of yellow-blue criterion) and only one less than the Stiles' $2^{\circ}$ colormixture functions by this test. It also indicates that the CIE and Judd color-mixture functions both correspond to very young observers in regard to balance point for the Granville grays.

The rank correlation (Spearman's) between $10^{6} / \theta_{2}$ for red-green balance and age of the observers at the $2^{\circ}$ position is 0.60 with an uncertainty of plus or minus 0.22 , the uncertainty being 4.9 times the probable error. Thus, it is suggested that there is a poor but significant correlation of lens and macular pigmentations with age. Figure 4 shows the correlation of $10^{6} / \Theta_{10}$ with age; the rank correlation is better being 0.76 plus or minus 0.13 . This correlation is attributable to the known increase in lens pigmentation with age. Here again, there are only six observers apparently less pigmented than Stiles' $10^{\circ}$ color-mixture functions. From figure 5 it will be noted that there is no correlation of macular pigmentation with age, the rank correlation being - 0.145 plus or minus 0.61 . Also, there is no significant correlation of macular or lens pigmentations with either eye color or hair color.

From table 5 and figures 3,4 , and 5 , it is possible to classify the oberservers and the four color-mixture functions into five groups, depending on their amounts of ocular pigmentation. From table 5, it will be seen that certain observers describe the simplex gray as redder than the complex at both the $10^{\circ}$ and $2^{\circ}$ positions. These are the young observers and those tentatively considered to have the least ocular pigmentation and constitute group 1. Those in group 2 apparently have a little more pigmentation and so call the simplex redder at the $10^{\circ}$ position but a match at the $2^{\circ}$ position. Group 3, comprising the majority of the observers, contains those who call the simplex redder at the $10^{\circ}$ position and greener at the $2^{\circ}$ position. With more pigmentation, the observers in group 4 call the simplex a match at the $10^{\circ}$ position and greener at the $2^{\circ}$ position. The most heavily pigmented observers, and these contain the oldest observers, call the simplex greener at both positions. Thus, these groups are called red-red, red-match, red-green, match-green, and green-green. The same grouping may be made with respect to the color temperature or reciprocal color temperature of the red-green balance points at the $10^{\circ}$ and $2^{\circ}$ positions. The three criteria for the five groups are 


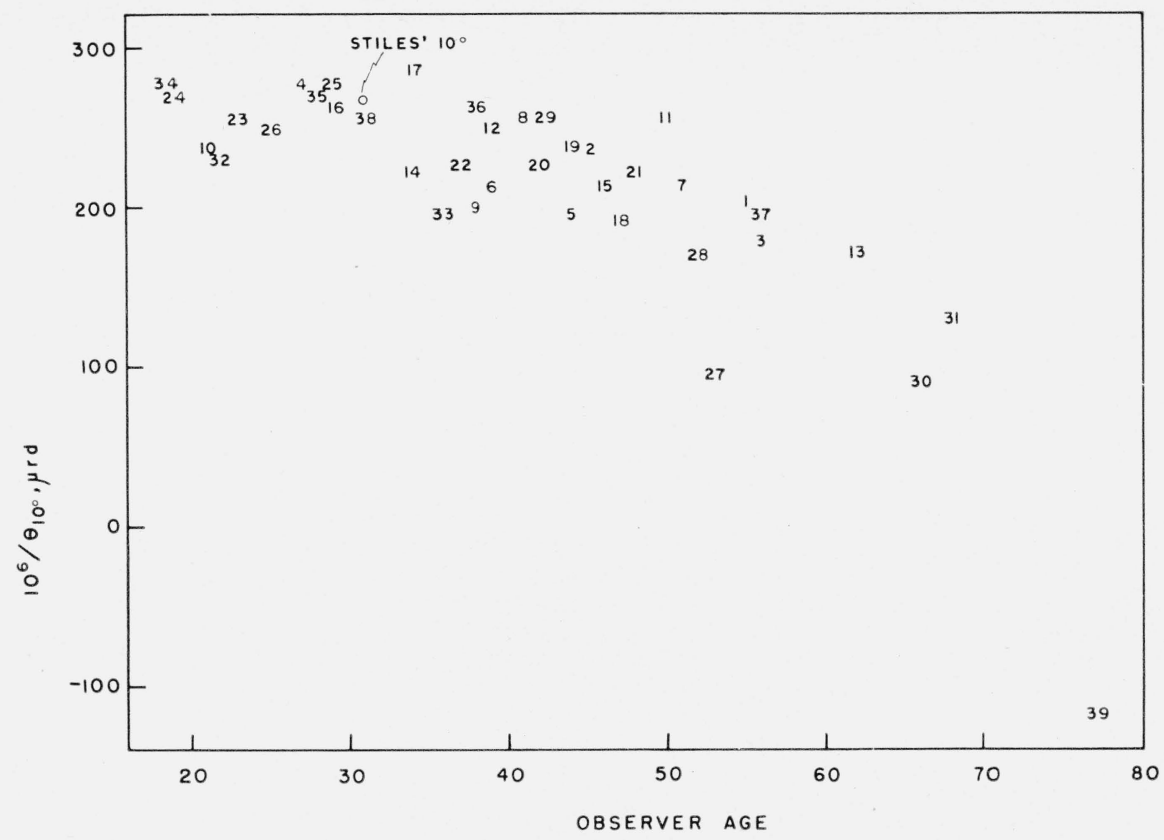

FIGURE 4. Reciprocal color temperature of source required in a $10^{\circ}$ field by 39 observers to produce red-green balance between the Granville grays plotted against observer age.

Note that older observers require lower reciprocal color temperatures. This result is ascribed to the known increase in lens pigmentation with age.

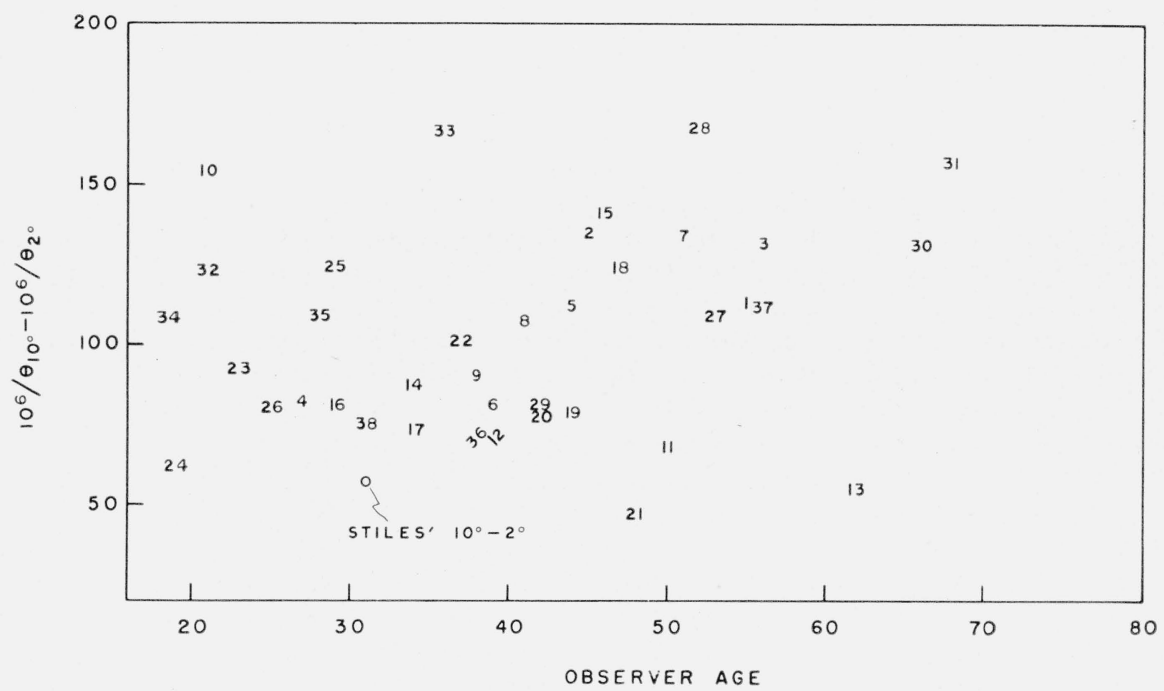

FIguRE 5. Difference between the reciprocal color temperatures required for $10^{\circ}$ and $2^{\circ}$ fields by 39 observers to produce red-green balance between the Granville grays.

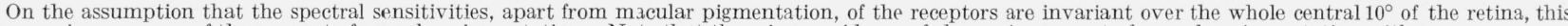
difference is a measure of the amount of macular pigmentation. Note that there is no evidence of change in amount of macular pigmentation with age

shown in table 6. According to this classification, all four color-mixture functions fall into the red-red group of very lightly pigmented observers with the CIE the most heavily pigmented and the Stiles' $10^{\circ}$ the least.

\section{Conclusions}

The reciprocal color temperature of the source required to produce red-green balance between the
Granville grays has been found to vary widely from one observer of normal color vision to another, and determination of this value of reciprocal color temperature for any one observer serves to characterize his color vision in an approximate but useful way. The value of reciprocal color temperature required in a $10^{\circ}$ field for red-green balance of the Granville grays is dependent on the amount of yellow pigmentation in the lens of the observer's eye, and is tentatively taken as a measure of this pigmenta- 
TABLE 6. Classification of observers into five groups according to indicated ocular pigmentation as shown by their description of the simplex gray relative to the complex gray for source $C$, and alternatively by the color temperature and reciprocal color temperature of source required to make neither gray redder or greener than the other

\begin{tabular}{|c|c|c|c|c|}
\hline Observer group & \multicolumn{2}{|c|}{ Simplex relative to complex } & $\begin{array}{l}\text { Color temperature of } \\
\text { source at match point }\end{array}$ & $\begin{array}{l}\text { Reciprocal color tempera- } \\
\text { ture of source at match }\end{array}$ \\
\hline $\begin{array}{l}\text { red-red } \\
\text { red-match } \\
\text { red-green } \\
\text { match-green } \\
\text { green-green }\end{array}$ & $\begin{array}{l}\text { red } 10^{\circ} \\
\text { red....... } \\
\text { red } \\
\text { match .... } \\
\text { green }\end{array}$ & $\begin{array}{l}\quad 2^{\circ} \\
\text { red } \\
\text { match } \\
\text { green } \\
\text { green } \\
\text { green }\end{array}$ & $\begin{array}{l}\Theta_{10^{\circ}}<\Theta_{2} \circ<6,750^{\circ} \\
\Theta_{10^{\circ}}<6,750^{\circ}=\boldsymbol{\theta}_{2} \circ \\
\Theta_{10^{\circ}}<6,750^{\circ}<\boldsymbol{\theta}_{2} \circ \\
\Theta_{10^{\circ}}=6,750^{\circ}<\Theta_{2} \circ \\
6,750^{\circ}<\Theta_{10^{\circ}}<\Theta_{2} \circ\end{array}$ & $\begin{array}{l}148<10^{6} / \Theta_{2} \circ<10^{5} / \Theta_{10} \circ \\
10^{6} / \Theta_{2} \circ=148<10^{6} / \Theta_{10^{\circ}} \\
10^{6} / \Theta_{2} \circ<148<10^{6} / \Theta_{10^{\circ}} \\
10^{6} / \Theta_{2} \circ<148=10^{5} / \Theta_{10} \circ \\
10^{6} / \Theta_{2} \circ<10^{\circ} / \Theta_{190}<148\end{array}$ \\
\hline
\end{tabular}

tion. Similarly, the value of reciprocal color temperature required in a $2^{\circ}$ field for red-green balance of the Granville grays is dependent both on lens pigment and on macular pigment, and the difference in these two values (value for $2^{\circ}$ field minus value for $10^{\circ}$ field) is tentatively taken as a measure of the macular pigmentation of the observer.

The tentative measure of lens pigmentation afforded by the Granville grays correlates well with the age of the observer, but the tentative measure of macular pigmentation shows no correlation with age. Neither measure shows significant correlation with eye color or hair color, but a tendency, significant at about the 15 percent level of confidence, was found for female observers to have less pigmented eyes than male observers of the same age.

The reciprocal color temperatures of source required by four sets of color-mixture functions for red-green balance of the Granville grays have been computed and found to be higher than the average value for 39 actual observers with normal color vision. Of the three sets of color-mixture functions intended to refer to $2^{\circ}$-field observation, the 1931 CIE standard observer agrees best. These data thus afford no basis for supplanting the 1931 CIE standard observer either with the Judd "i" colormixture functions or the 1955 Stiles' $2^{\circ}$ color-mixture functions for a pilot group of 10 observers.

With respect to these observations on the Granville grays, the Stiles' 1955 data for $2^{\circ}$ viewing does not fulfill the requirement recommended in 1955 by the CIE [1] that any revision of the "standard observer for colorimetry should represent average normal vision, adjusted as for an observer 30 years of age", but the data for $10^{\circ}$ viewing are fairly satisfactory in this regard.

\section{References}

[1] Comm. Internationale de L'Éclairage, Compt. rend., Zurich, p. II, sec. 1.3.1. (1955)

[2] W. C. Granville and D. B. Judd, Metameric color and the macular pigment, J. Opt. Soc. Am. 39, 632A (1949).

[3] A. E. Jacobsen, Non-adaptability of the ICI system to some near-whites which show absorption in the far-blue region of the spectrum, J. Opt. Soc. Am. 38, 442 (1948).

[4] D. B. Judd, A Maxwell triangle yielding uniform chromaticity scales, J. Research NBS 14, 41 (1935) RP756 J. Opt. Soc. Am. 25, 24 (1935).

[5] D. B. Judd, A comparison of direct colorimetry of titanium pigments with their indirect colorimetry based on spectrophotometry and a standard observer, J. Research NBS 43, 227 (1949) RP2024; J. Opt. Soc. Am. 39, 945 (1949) with errata in 40, 52 (1950).

[6] K. L. Kelly, Color designations for lights, J. Research NBS 31, 271 (1943) RP1565; J. Opt. Soc. Am. 33, 627 (1943).

[7] J. C. Maxwell, On the unequal sensibility of the foramen centrale to light of different colours, Reports British Association, p. 12 (1856)

[8] W. S. Stiles, Interim report to the Comm. Internationale de L'Eclairage, Zurich (1955) on the National Physical Labcratory's investigation of colour-matching (1955), Optica Acta 2, 168 (1955).

Washington, June 7, 1957. 